\title{
Targeted Review of EU Pharmaceutical Legislation - The Community Code on Medicinal Products Needs to Remain a Directive
}

\begin{abstract}
Christine Mellein and Jürgen Schwarze*
The Covid-19 pandemic has highlighted the need for timely access to medicinal products. With its Pharmaceutical Strategy, the European Commission intends to make the EU pharmaceutical system more future proof and crisis resistant. The identified measures shall be accompanied by a targeted review of the basic pharmaceutical legislation - consisting of Regulation (EC) No 726/2004 and Directive 2001/83/EC. The final form of the legislative instrument(s), ie whether this Directive shall stay a Directive or shall be merged into a Regulation is yet to be decided. This paper will look at these developments beyond the context of the pandemic and also consider the typical regulatory circumstances. The paper concludes that compared to a Regulation, the Directive remains the preferable legal instrument to provide the framework for nationally/decentralised authorised medicinal products. Both the Directive and the Regulation in their coexistence should continue being the main pillars of the basic EU pharmaceutical legislation.
\end{abstract}

\section{Introduction}

In the EU, medicinal products for human use are either authorised by the competent national authorities (NCAs) of the Member States or centralised by the European Commission (Commission) following the advice of the European Medicines Agency (EMA). This dual marketing authorisation system is routed in two basic legislative acts: Directive 2001/83/EC (Community Code) provides the regulatory framework for medicinal products authorised by Member States and Regulation (EC) No 726/2004² (EMA Regulation) lays down the Union wide (centralised) procedure.

\section{DOI: 10.21552/eplr/2021/1/4}

* Christine Mellein is Head of European and Public Law \& Governmental Affairs at Heel. For Correspondence: chris-

tine.mellein@heel.com. Prof Dr Dres hc Jürgen Schwarze is Professor Emeritus of German and Foreign Public Law, European Law and International Law at the University of Freiburg. For Correspondence: juergen.schwarze@jura.uni-freiburg.de.

1 Directive 2001/83/EC of 6 November 2001 on the Community code relating to medicinal products for human use [2001] OJ L311/67, as amended.

2 Regulation (EC) No 726/2004 of 31 March 2004 laying down Community procedures for the authorisation and supervision of medicinal products for human and veterinary use and establishing a European Medicines Agency (EMA) [2004] OJ L136/1, as amended.
In the wake of the Covid-19 pandemic the Commission is pursuing broad-ranging initiatives in the field of public health with ambitious timelines. It strives to build a stronger European Health Union. ${ }^{3}$ In its Pharmaceutical Strategy Roadmap of June $2020^{4}$ the Commission indicated that actions 'could also include a targeted evaluation and subsequent review of the basic pharmaceutical legislation', ie the Community Code and the EMA Regulation. The Communication on a Pharmaceutical Strategy for Europe of November $2020^{5}$ identified 'flagship initiatives' potentially requiring such a legislative review.

In March 2021, the Combined Evaluation Roadmap/Inception Impact Assessment document

3 President of the European Commission Ursula von der Leyen, 'State of the Union Address 2020' of 16.9.2020, <https://ec .europa.eu/info/sites/info/files/soteu_2020_en.pdf > accessed 21 April 2021; Commission, 'Communication on Building a European Health Union: Reinforcing the EU's resilience for crossborder health threats' $\operatorname{COM}(2020) 724$ final; for an overview on the planned measures cf < https://ec.europa.eu/info/strategy/ priorities-2019-2024/promoting-our-european-way-life/european -health-union_en> accessed 21 April 2021.

4 Commission, 'Roadmap to Pharmaceutical Strategy - Timely patient access to affordable medicines' Ref. Ares(2020)2858413 3.

5 Commission, 'Communication on a Pharmaceutical Strategy' $\operatorname{COM}(2020) 761$ final. 
related to the 'Evaluation and revision of the general pharmaceutical legislation' became available (Evaluation Roadmap). There the Commission stated: 'The evaluation will not cover all the provisions of the legislations and focus on those that relate to the objectives of the Pharmaceutical Strategy for Europe and presented in this roadmap. ${ }^{6}$ The document concluded: 'The revision concerns a Regulation and a Directive. The final form of the legislative instrument(s) is yet to be decided."

Regarding the legislative instruments there are, realistically, two basic options: Either the coexistence of a Directive (Community Code) with a Regulation (EMA Regulation) will be kept (first option) or the Community Code and the EMA Regulation will be merged into one Regulation (second option). ${ }^{8}$

This article firstly (Section II) summarises the evolution, legal effect and main content of the Community Code and the EMA Regulation and evaluates the structure of their coexistence. Section III contains an assessment from the practical perspective. Section IV recalls the available opinions voiced by Member States on the REFIT Platform in 2019. The experiences of previous revisions particularly concerning veterinary medicinal products and clinical trials are described in Section V. Relevant considerations derived from primary EU law follow under Section VI. The conclusion (Section VII) is that the Community Code's legal form of a Directive should be maintained.

6 Commission, 'Combined Evaluation Roadmap/Inception Impact Assessment' Ref. Ares(2021)2185074, 2.

7 ibid 6 .

8 Theoretically there are further less realistic options.

9 Eg Council Directive 65/65/EEC of 26 January 1965 on the approximation of provisions laid down by Law, Regulation or Administrative Action relating to proprietary medicinal products [1965] OJ 22/369; Council Directive 89/343/EEC of 3 May 1989 extending the scope of Directives 65/65/EEC and 75/319/EEC and laying down additional provisions for radiopharmaceuticals [1989] OJ L142/16; Council Directive 92/25/EEC of 31 March 1992 on the wholesale distribution of medicinal products for human use [1992] OJ L113/1; Council Directive 92/28/EEC of 31 March 1992 on the advertising of medicinal products for human use [1992] OJ L113/13.

10 Consolidated Version of the Treaty establishing the European Community [1997] (Amsterdam), OJ C340/173

11 Directive 2010/84/EU of 15 December 2010 amending, as regards pharmacovigilance, Directive 2001/83/EC on the Community code relating to medicinal products for human use [2010] OJ L348/74.

12 Directive 2011/62/EU of 8 June 2011 amending Directive 2001/83/EC on the Community code relating to medicinal prod-

\section{Community Code and EMA Regulation: Evolution, Legal Effect, Content and Structural Analysis}

\section{Evolution and Legal Effect}

The Community Code codified various previous medicinal products related directives in one single text in 2001. ${ }^{9}$ It was based on the approximation of laws provision (then Article $95 \mathrm{TEC}^{10}$ ) to enable patients' access to safe medicinal products within a fair common market. It has been continuously updated. Major amendments were included by Directive 2010/84/EU on pharmacovigilance ${ }^{11}$ and Directive 2011/62/EU related to falsified medicinal products ${ }^{12}$.

As foreseen in the Treaties, a Directive shall be binding, as to the result to be achieved, upon each Member State to which it is addressed, but shall leave to the national authorities the choice of form and methods (Article 288 TFEU $^{13}$ ). EU Member States are obliged to implement the content of Directives into their national law. As Article 130 reiterates, the Community Code addresses the Member States which have implemented it into their national laws ${ }^{14}$, eg into 'Arzneimittelgesetz' (AMG) ${ }^{15}$ in Germany, 'Code de la santé publique' ${ }^{16}$ in France, 'Decreto Legislativo ${ }^{17}$ in Italy, 'Ley 29/2006 de 26 de julio, de garantías y uso racional de los medicamentos y productos sanitarios' $^{18}$ in Spain, 'Prawo farmaceutyczne ${ }^{19}$ in Poland, 'Geneesmiddelenwet' ${ }^{20}$ in Netherlands, 'Arrêté royal relatif aux médicaments à usage humain et vétéri-

ucts for human use, as regards the prevention of the entry into the legal supply chain of falsified medicinal products [2011] O] L174/74.

13 Consolidated Version of the Treaty of Lisbon on the Functioning of the European Union [2012] OJ C326/47.

14 cf the overview on national transposition measures communicated by Member States to the Commission: <https://eur-lex.europa .eu/legal-content/DE/NIM/?uri=celex:32001L0083> accessed 21 April 2021.

15 German Medicinal Products Act of 1976, BGBI. (OJ) 1976/110 as amended by 12 . Amending Law to the German Medicinal Products Act of 30.7.2004, BGBI. (OJ) 2004/41, 2031.

16 Public health code, as amended by Decree No 2004-83 of 23.1.2004, JORF (OJ) No 22 of 27.1.2004.

17 Legislative Decree No 219 of 24.4.2006, GU (OJ) No 2006/142 of $21.6 .2006,2$.

18 Law 29/2006, BOE (OJ) No 178 of 27.7.2006, as amended.

19 Polish Medicines Act of 20.4.2004, Dziennik Ustaw (OJ) No 92.

20 Dutch Medicines Act (DMA) of 8.2.2007, OJ of 20.3.2007. 
naire ${ }^{\prime 21}$ in Belgium, 'Läkemedelsverkets föreskrifter ${ }^{22}$ in Sweden, 'Arzneimittelgesetz ${ }^{23}$ in Austria.

The EMA Regulation was based on Articles 95 and 152(4)(b) TEC. ${ }^{24}$ It replaced Regulation (EEC) No 2309/93 which had already laid down Community procedures for certain medicinal products (high-technology medicinal products, particularly those derived from biotechnology) and had established the European Agency for the Evaluation of Medicinal Products (EMEA). ${ }^{25}$ The centralised procedure was expanded on further categories of medicinal products in 2004 and the EMA Regulation has been continuously amended since then.

A Regulation shall have general application and be binding in its entirety and directly applicable in all Member States (Article 288 TFEU). This is reiterated in Article 90 EMA Regulation. Transposition into national law is not required. National provisions on issues already regulated in a Regulation are only permissible under narrow conditions. ${ }^{26}$

The Community Code and the EMA Regulation are the two core pillars of a broader EU acquis for human medicinal products, including amongst others, legislation to govern medicinal products for children ${ }^{27}$, rare diseases ${ }^{28}$, advanced therapies ${ }^{29}$, clinical trials $^{30}$, pharmacovigilance ${ }^{31}$, variations ${ }^{32}$ and $\mathrm{GMP}^{33}$.

21 Royal Decree of 14.12.2006, Belgisch Staatsblad (OJ) No 2006023298 of 22.12.2006, 74016.

22 Swedish Regulation amending the Medical Products Agency's Regulations and General Guidelines (LVFS 1995:8) of 23.9.2003, LVFS (OJ) 2003:8 of 1.10.2003.

23 Austrian Medicinal Products Act of 1983, BGBI. (OJ) No $185 / 1983$ as amended by Law of 28.12.2005, BGBI. (OJ) No $153 / 2005$.

24 (n 10). Art 95 TEC was corresponding to ex-Art 100a TEEC.

25 cf Kai Purnhagen, 'The Challenge of Globalization in Pharmaceutical Law - Is an International Drug Approval System Modeled after the European System Worth Considering?' (2008) Food and Drug Law Journal 623, $635 \mathrm{f}$.

26 cf below under V.1.b).

27 Regulation (EC) No 1901/2006 of 12 December 2006 on medicinal products for paediatric use and amending Regulation (EEC) No 1768/92, Directive 2001/20/EC, Directive 2001/83/EC and Regulation (EC) No 726/2004 [2006] OJ L378/1.

28 Regulation (EC) No 141/2000 of 16 December 1999 on orphan medicinal products [2000] OJ L18/1.

29 Regulation (EC) No 1394/2007 of 13 November 2007 on advanced therapy medicinal products and amending Directive 2001/83/EC and Regulation (EC) No 726/2004 [2007] O] L324/121.

30 Regulation (EU) No 536/2014 of 16 April 2014 on clinical trials on medicinal products for human use, and repealing Directive 2001/20/EC [2014] OJ L158/1.

31 Directive 2010/84/EU of 15 December 2010 amending, as regards pharmacovigilance, Directive 2001/83/EC on the Com-

\section{Authorisation Requirement}

According to Article 6(1) Community Code, no medicinal product may be placed on the market of a Member State unless a marketing authorisation has been issued. This prohibition refers to both, marketing authorisations granted in accordance with the Community Code and the EMA Regulation. Based on Article 5(2) Community Code Member States may, however, temporarily allow the distribution of unauthorised medicinal products in response to amongst others the suspected or confirmed spread of pathogenic agents or toxins which could cause harm. ${ }^{34} \mathrm{Ap}$ parently based on this exemption as nationally implemented, few Member States (eg Hungary, Slovakia, Czech Republic) allowed or considered allowing the distribution of the COVID-19 vaccine 'Sputnik $V^{\prime}$ in their territories. ${ }^{35}$

\section{Scope, Centralised and National/Decentralised Procedures}

The Community Code applies to medicinal products for human use to be placed on the market in Member States and prepared industrially or manufactured

munity code relating to medicinal products for human use [2010] OJ L348/74; Regulation (EU) No 1235/2010 of 15 December 2010 amending, as regards pharmacovigilance of medicinal products for human use, Regulation (EC) No 726/2004 laying down Community procedures for the authorisation and supervision of medicinal products for human and veterinary use and establishing a European Medicines Agency, and Regulation (EC) No 1394/2007 on advanced therapy medicinal products [2010] OJ L348/1.

32 Commission Regulation (EC) No 1234/2008 of 24 November 2008 concerning the examination of variations to the terms of marketing authorisations for medicinal products for human use and veterinary medicinal products [2008] OJ L334/7.

33 Commission Delegated Regulation (EU) No 1252/2014 of 28 May 2014 supplementing Directive 2001/83/EC with regard to principles and guidelines of good manufacturing practice for active substances for medicinal products for human use [2014] OJ L337/1; Commission Directive 2003/94/EC of 8 October 2003 laying down the principles and guidelines of good manufacturing practice in respect of medicinal products for human use and investigational medicinal products for human use [2003] O] L262/22.

34 An emergency use authorisation as known from the US (Section 564 of the Federal Food, Drug, and Cosmetic Act (21 USC)) is neither foreseen in the EMA Regulation nor in the Community Code.

35 Cf in more detail Markus Ambrosius/Lukas Klement, 'Die Zulassung von Arzneimitteln zur Behandlung von COVID-19 und zur Bekämpfung der Pandemie' (2021) PharmR 119, 125. For a perspective from previous epidemics cf Marco Rizzi, 'The road to a Vaccine for COVID-19: Regulatory and Policy Infrastructure, Incentives and Obstacles' (2020) EPLR, 98, 100 
by a method involving an industrial process (Article 2(1) Community Code). The EMA Regulation lays down the Community procedures for the (centralised) authorisation, supervision and pharmacovigilance of medicinal products and established the EMA (Article 1 EMA Regulation).

Article 3(1) EMA Regulation in conjunction with its Annex provides an enumerative list of medicinal products requiring centralised marketing authorisation. Included are medicinal products derived from certain biotechnological processes, advanced therapy medicinal products, medicinal products containing a new active substance for the treatment of specific diseases and orphan medicinal products. For them the centralised procedure is mandatory. As current examples, COVID-19 mRNA vaccines ${ }^{36}$ and COVID-19 vector vaccines ${ }^{37}$ were subject to the mandatory centralised procedure within Article 3(1) EMA Regulation and point 1 Annex I as these vaccines are prepared by using specific biotechnological processes. Remdesivir ${ }^{38}$ was centrally authorised for specific treatment of COVID-19 based on Article 3(1) EMA Regulation and point 3 Annex I (new active substance in this indication). ${ }^{39}$ These marketing authorisations were issued conditionally ${ }^{40}$ requiring annual renewal as medicinal products to be used in emergency situations in response to public health threats (Article 14-a EMA Regulation in conjunction with Article 2(2) Regulation No 507/2006) ${ }^{41}$.

36 Comirnaty, Marketing Authorisation Holder: BioNTech Manufacturing GmbH; COVID-19 Vaccine Moderna, Marketing Authorisation Holder: Moderna Biotech Spain, S.L.

37 Vaxzevria, Marketing Authorisation Holder: AstraZeneca AB; COVID-19 Vaccine Janssen, Marketing Authorisation Holder: Janssen-Cilag International NV.

38 Veklury, Marketing Authorisation Holder: Gilead Sciences Ireland UC.

39 Ambrosius/Klement ( $\mathrm{n}$ 35) $120 \mathrm{f}$.

40 In more detail Ambrosius/Klement (n 35) 123; in general on the conditional marketing authorisation of Kaat Van Delm, 'Accelerated Access to Medicinal Products' (2020) EPLR 192, 198.

41 Commission Regulation (EC) No 507/2006 of 29 March 2006 on the conditional marketing authorisation for medicinal products for human use falling within the scope of Regulation (EC) No $726 / 2004$ of the European Parliament and of the Council [2006] OJ L92/6.

42 Van Delm (n 40) $201 \mathrm{f}$; for an overview on the further requirements in some Member States: Marc Christian Bauer, 'Expanded Access Programs in the European Union - Practical Tips and Pitfalls' (2020) EPLR 1, 4

43 Eg Art 2 Regulation (EU) No 536/2014 on clinical trials (n 30), Art 2 Commission Directive 2003/94 on GMP (n 33).

44 Purnhagen (n 25) 623, $636 \mathrm{f}$.
According to Article 3(2) EMA Regulation the centralised procedure is optional for medicinal products with new active substances, with significant therapeutic, scientific or technical innovation and for which the authorisation is in the interest of patients at Community level. If these criteria are met the applicant decides whether to pursue the centralised or the national/decentralised procedure. Furthermore, under limited specific circumstances according to Article 83 EMA Regulation Member States may make a not yet authorised medicinal product falling into the scope of Article 3(1) or (2) EMA Regulation available for compassionate use. ${ }^{42}$

Medicinal products outside the scope of Article 3 EMA Regulation need to be authorised nationally/decentralised by the NCAs according to the procedures of the Community Code as implemented in the respective national laws. As illustrated below the majority of marketing authorisations are granted by NCAs, either in one Member State or via the decentralised/mutual recognition procedure (DCP/MRP) for more than one Member State.

Article 1 Community Code contains the relevant definitions. Reference to these definitions is made in Article 2 EMA Regulation and in further secondary EU law. ${ }^{43}$

Article 8(3) Community Code requires that the applications are done in accordance with the Community Code's Annex I. The basic procedures relevant to marketing authorisation including tasks of marketing authorisation holders and NCAs, renewals, grounds for refusals, MRP and DCP can be found in Articles 17 to 39 Community Code. An application for marketing authorisation shall be refused if the quality, safety or efficacy requirements are not fulfilled (Article 26(1) Community Code). In MRP and DCP, the application is first made in the reference Member State (RMS). Then the concerned Member States (CMS) selected by the applicant may recognise the authorisation of the RMS. In case a CMS identifies a potential serious risk to public health the procedure may become cumbersome with involvement of the coordination group composed of representatives of the Member States and potential involvement of EMA's Committee for Human Medicinal Products (CHMP) and the Commission (Articles 29 to $34 \mathrm{Com}^{-}$ munity Code). ${ }^{44}$

The further requirements for the marketing authorisation application and specific provisions for certain product categories (eg generic, well-established 
use, homeopathic and traditional herbal medicinal products) can be found in Articles 8 to $16 \mathrm{i} \mathrm{Commu-}$ nity Code.

Responsibilities and the procedure for centralised marketing authorisations are described in Articles 4 to 15 EMA Regulation. The application made to EMA needs to include all necessary data related to quality, safety and efficacy. To speed up EMA's assessment during the COVID-19 pandemic EMA is allowing a 'rolling review'. It was/is used by above mentioned COVID-19 related marketing authorisations and currently prepared/pending applications $^{45}$. In the rolling review EMA's CHMP reviews available data from ongoing studies prior to the formal application. Once CHMP decides that there are sufficient data for an application the applicant submits its formal application. ${ }^{46}$ This rolling review procedure is not routed in the EMA Regulation. EMA, acting particularly through its committees shall, however, advise companies on the conduct of tests and trials necessary to demonstrate quality, safety and efficacy (scientific advice, Article 57(1)(n) EMA Regulation). The rolling review has in fact accelerated granting marketing authorisations for many COVID-19 related medicinal products.

For the application requirements and the dossier structure the EMA Regulation refers to the Community Code including its Annex I. The centralised marketing authorisation is granted by the Commission. The CHMP draws up the opinion of EMA. A centralised marketing authorisation is valid throughout the whole Community, ie all Member States (Article 13 EMA Regulation). ${ }^{47}$ An application shall be refused if the quality, safety or efficacy requirements are not fulfilled (Article 12(1) EMA Regulation).

The establishment, responsibilities and composition including committees of EMA are provided for in Articles 55 to 66 EMA Regulation. EMA has legal personality (Article 71 EMA Regulation). The committees (eg CHMP and the Pharmacovigilance Risk Assessment Committee (PRAC)) include a representative from each Member State. The CHMP may establish scientific advisory groups in connection with the evaluation of specific types of medicinal products or treatments (Article 56(2) EMA Regulation). CHMP and PRAC have certain functions under the Community Code as well. In collaboration with the Member States and the Commission, EMA set up and maintains the Eudravigilance database and the European medicines web-portal (Articles 24, 26 EMA Regulation).

The general concept of this dual system for marketing authorisations was established 1993 and has used the current basic structure since 2004. It has raised little criticism, neither by EMA nor NCAs nor the companies being the marketing authorisation holders.

\section{Manufacture, Distribution, Pharmacovigilance and Surveillance}

According to the rules on manufacture and importation (Articles 40 - 53 Community Code) and on wholesale and brokering (Articles 76 to $85 \mathrm{~b}$ Community Code) NCAs issue the manufacturing (Article 42(1) Community Code) and distribution authorisations (Article 78 Community Code). Provisions on pharmacovigilance (Articles 101 to Article 108b Community Code) were broadened with Directive 2010/84/EU and contain comprehensive obligations for marketing authorisation holders and the NCAs. Generally, it is the task of the NCAs to ensure compliance with the Community Code's requirements and to carry out the necessary inspections (Article 111 Community Code).

Articles 16 to 20 EMA Regulation contain the provisions on supervision and penalties related to centrally authorised medicinal products. As a basic principle NCAs perform the manufacturing, import and pharmacovigilance supervision within the EU territory also related to centrally authorised medicinal products (Article 18 EMA Regulation). The rules on pharmacovigilance follow in Articles 21 to 29 EMA Regulation. Here, again reference is made to the Community Code's pharmacovigilance requirements.

Over the last few decades the administration and enforcement of EU pharmaceutical legislation - in line with the administrative autonomy of Member

45 cf EMA, Covid-19 vaccines: under evaluation, <https://www.ema .europa.eu/en/human-regulatory/overview/public-health-threats/ coronavirus-disease-covid-19/treatments-vaccines/vaccines-covid -19/covid-19-vaccines-under-evaluation> accessed 21 April 2021.

46 cf EMA, Initiatives for acceleration, 3, 4, <https://www.ema .europa.eu/en/documents/other/ema-initiatives-acceleration -development-support-evaluation-procedures-covid-19-treatments -vaccines_en.pdf> accessed 21 April 2021.

47 Also the EFTA States based on the Decision of the EEA Joint Committee No 61/2009 of 29 May 2009 incorporated the EMA Regulation into the EEA Agreement. 
States - has to a large extent been ensured by NCAs. Again, this system has hardly been criticised.

\section{Implementation of Community Code into National Law}

As a Directive, the Community Code and its amendments need to be implemented into each Member State's national law. Therefore, the legal basis for the marketing authorisations issued by NCAs is the national law. In Germany the $\mathrm{AMG}^{48}$ had already been introduced in 1961 even before the first EU pharmaceutical legislation ${ }^{49}$ was adopted. Since 1976 when the general authorisation requirement was included, the AMG has been continuously updated in line with the EU secondary law, in particular the Community Code. ${ }^{50}$ Many further national medicinal product laws have a long tradition, eg France ${ }^{51}$, Belgium $^{52}$ and Austria. ${ }^{53}$

\section{Established Structure}

The basic structure of the general EU pharmaceutical legislation (Community Code and EMA Regulation) which is in place since 2004 (entry into force of EMA Regulation) can be summarised as follows: Medicinal products need to be authorised. Specific medicinal products mandatorily or optionally require a centralised authorisation issued by the Commission (Article 3(1), (2) EMA Regulation). In the centralised procedure the scientific assessments are performed

48 Arzneimittelgesetz (n 15).

49 Directive 65/65/EEC of 26 January 1965 on the approximation of provisions laid down by law, regulation or administrative action relating to proprietary medicinal products [1965] OJ 369/65.

50 Wolfgang Rehmann, AMG (5th edn, C.H.Beck 2020) intro paras 2-9.

51 Code de la santé publique of 7.10.1953, JORF 237/1953.

52 Loi sur les medicaments of 25.3.1964, Moniteur Belge 1964, 4206.

53 Arzneimittelgesetz of 2.3.1983, BGBI. 185/1983.

54 cf Florian Schmidt/Satish Sule, 'Von Patenten und Patienten - Die Entwicklung des EU-Gesundheitsrechts seit Lissabon' (2012) EuZW 369, 371 ff; Andreas Fleischfresser in Stefan Fuhrmann/Bodo Klein/Andreas Fleischfresser (eds), Arzneimittelrecht (3rd edn, Nomos 2020) $§ 3$ para $71 \mathrm{f}$

55 Commission Delegated Regulation (EU) 2021/756 of 24 March 2021 amending Regulation (EC) No 1234/2008 (Variation Regulation) [2021] OJ L162/1. The new Regulation is based on Art 23(b) Community Code and Art 16a(3) EMA Regulation. by EMA's CHMP which may involve specialised advisory groups. The applications for the majority of medicinal products need to be filed nationally to the NCA and may be recognised in other Member States via a MRP or DCP. For both the centralised and the national/decentralised procedures the applicable definitions and the application requirements are the same as the EMA Regulation refers to the respective provisions of the Community Code. The expertise of the Member States' representatives in the centralised procedures is available via the committees, particularly the CHMP. The principle databases applicable for all medicinal products in the EU are run by EMA.

The architecture is logical. Via the references in the EMA Regulation to the Community Code the core standards are the same, independently from the applicable procedure. Different from a Regulation, the Community Code as a Directive allows and requires for the national/decentralised procedures the further existence of the national medicinal products laws which regularly have their own long history. During the long-term practical use of this structure legal certainty has been enhanced by the continuous evolution of a differentiated case law by the EU's Court of Justice (CJEU) and General Court (EGC). ${ }^{54}$ Via the involved committees the centralised procedures depend on the expertise of the representatives from NCAs. It is important to keep the national practices in place to have this expertise available on the EMA level.

\section{Suitability for 'Targeted' Amendments}

As shown above, the EMA Regulation via the conditional marketing authorisation and the accelerated assessment allows to speed up the centralised procedure eg during a pandemic. Under limited conditions the Community Code may allow the temporary distribution of certain unauthorised medicinal products by Member States. Adjustments in the legislation, eg the incorporation of the rolling review, more flexibility and clearer rules for the 'allowance' of medicinal products during emergency cases are necessary. Technically, such adjustments and further improvements, eg for the MRP and DCP, can be included into the Community Code and the EMA Regulation or addressed by means of delegated or implementing acts as the Commission's recent legislative initiative to speed up the variation process of adapted vaccines against COVID-19 exemplifies. ${ }^{55}$ 


\section{a. Commission's 'Targeted Approach'}

In 2020 the Commission indicated that it would perform 'a targeted evaluation and subsequent review of the basic pharmaceutical legislation. ${ }^{56}$ In March 2021 it confirmed that this evaluation 'will not cover all the provisions of the legislations and focus on those that relate to the objectives of the Pharmaceutical Strategy for Europe and presented in this roadmap. ${ }^{57}$

The terms 'targeted evaluation' or 'targeted approach' in the context of legislative reviews are not defined in EU law. As the Commission stated it simply means that within the basic/general pharmaceutical legislation (Community Code and EMA Regulation) certain provisions (Articles) will be identified for review (amendments). Other Articles for which no action is identified remain unaffected. As no full review is planned this implies that the Commission still considers the main parts of the existing legislation as fit for purpose. This reflects the Commission's better regulation policy to first identify certain provisions or parts of an existing legislation and articulate the need for revision for such provisions prior to amending a legislation in its totality. ${ }^{58}$

Using the current structure for the 'targeted approach' is straightforward and pragmatic. If an existing Directive were transposed into a Regulation its content would apply directly. All former provisions related to the duties of the Member States would need to be re-phrased. The national laws implementing the former Directive would become obsolete and to a broad extent would need to be repealed. Transitory provisions would be required. If an existing Directive were merged into/with an existing Regulation (eg Community Code into/with EMA Regulation) the process would become even more complicated. Then, additionally, vast parts of the whole structure of both former legal acts would need to be newly organised. As illustrated below (under Section V), recent revisions, particularly on veterinary medicinal products and on clinical trials, show that such a fundamental break with an established structure already from the pure technical perspective constitutes a time-consuming and error-prone challenge. The positioning of each existing provision within the new structure needs to be considered, independent of whether its content shall be amended or not. Depending on the subject this may be indicated for certain full revisions, but not for the here envisaged 'target- ed' review to be performed within ambitious timelines. ${ }^{59}$

\section{b. Topics Identified by the Commission Requiring Potential Amendments}

The Commission's recent initiative on the 'Evaluation and revision of the general pharmaceutical legislation' is driven by 4 objectives $^{60}:(1)^{`}$ Ensure access to affordable medicines for patients, and address unmet medical needs', (2) 'Enable innovation for the development of high quality, safe, effective medicines, harnessing the benefits of digital and emerging science and technology while reducing the environmental footprint', (3) 'Enhance the security of supply of medicines and address shortages', (4) 'Reduce regulatory burden and provide a flexible regulatory framework'. In this document, the Commission lists 5 specific issues the initiative aims to tackle and 14 elements to be covered by policy options. ${ }^{61}$

It is not the purpose of this article and would be premature to analyse how the identified topics may be concretely implemented within a legislative review. To tackle this complex task, the Commission will - in line with the Better Regulation Tools - collect extensive evidence, undertake consultations ${ }^{62}$ and draft an Impact Assessment.

However, from a more general perspective and in order not to counteract the initiative's objective to 'reduce regulatory burden and provide a flexible regulatory framework' ${ }^{63}$ it will be crucial to maintain established and functioning structures, procedures and responsibilities. It will also be important to keep different topics separated instead of overloading the

\footnotetext{
56 (n 4).

57 (n 6).

58 cf Commission, 'Better Regulation guidelines and toolbox', $<$ https://ec.europa.eu/info/law/law-making-process/planning-and -proposing-law/better-regulation-why-and-how/better-regulation -guidelines-and-toolbox_en> accessed 21 April 2021.

$59 \mathrm{cf}$ on the planning of EU action: Commission, 'Better Regulation guidelines - planning', <https://ec.europa.eu/info/sites/info/files/ better-regulation-guidelines-planning.pdf $>$ accessed 21 April 2021.

60 (n 6) 3

61 ibid 2 and $3 \mathrm{f}$.

62 cf Commission, 'Consultation strategy for the evaluation and revision of the general pharmaceutical acts under the Pharmaceutical Strategy for Europe', <https://ec.europa.eu/health/sites/ health/files/human-use/docs/consultation-strategy_20210330.pdf $>$ accessed 21 April 2021.

63 (n 6) 3, policy option under (b).
} 
scope and content of one specific piece of legislation. By doing so the identified issues being in the scope of the Community Code and/or the EMA Regulation (eg adaption to new technology, faster and more flexible procedures etc) should be solvable by amending the affected provisions. This has the major advantage of leaving the functioning existing structures and responsibilities unaffected. As described under Section IV below, this was also the view of many Member States contributing to a 2019 REFIT Platform Opinion on a proposal to re-issue the Community Code as a Regulation.

\section{First Take-Away (Formal Perspective)}

The centralised procedure involving the Commission and EMA is a Union procedure and such an authorisation is valid for the whole EU. It is obvious that the Regulation is the most suitable legal form for this procedure. In contrast to that, the national/decentralised procedures are filed with the NCAs and are assessed according to the national law implementing the Community Code. The requirements for the national authorisations are well harmonised via the Community Code (Directive). For the Community Code a switch of the legal form from currently a Directive to a Regulation is a theoretical option. Such a fundamental change would, however, have drastic effects: Almost all established provisions in national laws on medicinal products would become obsolete.

64 Commission, 'Union Register of medicinal products for human

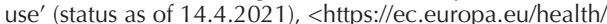
documents/community-register/html/reg_hum_act.htm?sort=a>.

65 Figure derived from BfArM, 'Statistics on Marketable Products in the Responsibility of the BfArM' (status as of 16.4.2021), <https:// www.bfarm.de/EN/Service/Statistics/Licensing/statistic-verkf-am -zustBfArM-en.html>.

66 Figures derived from BfArM, 'Current Processing Statistics' (status as of 15.4.2021), <https://www.bfarm.de/EN/Service/Statistics/ Licensing/Statistic_bearbeitung-aktuell_Maer21en.html> 5 .

67 There are currently around 11.270 medicinal products authorised, thereof the centrally authorised products need to be deducted; source: Agenzia Italiana del Farmaco (AIFA), <https:// www.aifa.gov.it/dati-aifa> and <https://www.aifa.gov.it/web/guest/ liste-dei-farmaci> accessed 21 April 2021.

68 There were 18.769 medicinal products authorised end of 2019 , thereof the centrally authorised products need to be deducted; source: Annual report 2019 of Agencia Española de Medicamentos y Productos Sanitarios (AEMPS), 'Memoria 2019' (July 2020), 16, 25, <https://www.aemps.gob.es/laAEMPS/ memoria/docs/memoria-2019.pdf?x35385> accessed 21 April 2021.

69 ibid 16, 23-25
According to the Commission's envisaged approach, only identified provisions shall be evaluated and if necessary, amended while the others shall remain unaffected. Such a 'targeted approach', particularly when to be performed within ambitious timelines, should not break with the existing grown and reasonable general structure consisting of the Community Code and EMA Regulation. Instead, at least from a formal/technical perspective, the amendments of the identified provisions should be performed within the existing structure either by amending the affected Articles or via implementing or delegated acts.

\section{Evaluation of the Dual Approach from the Practical Perspective}

In the following, the practical relevance of the coexistence of the Community Code and EMA Regulation shall be analysed.

\section{Relevance of Decentralised/National Authorisations Based on Community Code}

The majority of medicinal products is authorised according to national law implementing the Community Code. Whereas around 1.200 medicinal products for human use ${ }^{64}$ possess active centralised marketing authorisations, in the Member States by far more medicinal products are authorised by the NCAs, either in the DCP/MRP or a purely national procedure.

In Germany currently exist around 38.000 medicinal products formally authorised/registered by the Federal Institute for Drugs and Medical Devices (BfArM). ${ }^{65}$ Solely from January until March 2021 BfArM received 431 applications for marketing authorisations, 415 thereof for medicinal products with known substances; MRP and DCP were also frequently used. ${ }^{66}$ By our calculations, in Italy there are currently more than $10.000^{67}$ and in Spain more than $17.000^{68}$ medicinal products nationally/decentralised authorised. In 2019 the Spanish Agency for Medicinal Products and Medical Devices (AEMPS) authorised around 800 medicinal products for human use via MRP and DCP and around 365 nationally. ${ }^{69}$ These figures show the practical importance of the national authorisation and the MRP/DCP and that the na- 
tional experience with marketing authorisation procedures is widespread. Via EMA's committees (CHMP, PRAC) this nationally gained expertise is available in centralised procedures.

Nationally authorised medicinal products are often non-prescription medicinal products for selfmedication. They well support the routine care of patients in Member States' health systems and are an inherent part of health care related to the patient's own responsibility for his personal health. To exemplify the tradition: Around 6.900 currently in Germany officially authorised/registered medicinal products even refer back to medicinal products which had been already available in $1976 .^{70}$

Depending on the different traditions and habits, patients', pharmacists' and health care professionals', demand varies regionally. The range of nationally authorised medicinal products in the different regions may differ accordingly and there are companies with strong regional focuses. The national procedure or MRP/DCP with targeted selections of CMS allow focus in certain regions. Similarly, the NCAs are long term familiar with the traditions in their Member States and some structure their organigram accordingly. ${ }^{71}$

Against this background the national procedure and MRP/DCP are particularly important for SMEs who may have regional focuses, may distribute medicinal products with known substances and/or may not easily afford the centralised procedure. This is the reason why many of the known brands often used by patients in self-medication belong to SMEs. If the content of the Community Code were to be included in a Regulation the administrative costs of the implementation and particularly the impact on SMEs would be considerable. If the Commission considered such a switch the related implications on SMEs should be made subject to an in-depth analysis by way of an external study prior to breaking with the current dual structure.

\section{Relevance of Centralised Authorisations According to EMA Regulation}

According to the EU Union Register of medicinal products for human use there are around 1.200 active centrally authorised medicinal products. The centralised procedure is mandatory/optional for a limited list of certain medicinal products, others are ex- cluded from this procedure. Centrally issued marketing authorisations are valid throughout the whole EU. In the procedure and in scientific advices the companies have with the EMA one basic contact point ('one shop stop' principle). ${ }^{72}$ This is a clear advantage compared to MRP/DCP in which different NCAs are involved. When dealing with highly innovative medicinal products with new substances or new techniques, sophisticated assessments with shared expertise performed by the CHMP and its specialised scientific advisory groups are necessary. These advantages (one shop stop principle, possibility to perform sophisticated assessments) underline the importance of the centralised procedure for certain medicinal products.

\section{Fees for the Centralised and National Procedures}

From the applicant's perspective the amount of fees is also of importance. Fees paid to EMA for a full centralised marketing authorisation are from EUR 296.500 upwards. ${ }^{73}$ The fees for the nationally granted marketing authorisations need to be derived from the respective national fee regulation. In Germany the maximum fee for a national marketing authorisation is 57.800 EUR. $^{74}$

\section{Second Take-Away (Practical Perspective)}

For certain medicinal products - particularly those requiring complex assessments - the centralised pro-

70 (n 65), there referred to as 'Nachzulassungen/Nachregistrierungen' (post-marketing authorisations/post-marketing registrations)

71 cf structure of BfArM, <https://www.bfarm.de/SharedDocs/ Downloads/EN/BfArM/Org/bfarm_organigramm-en.pdf?_blob $=$ publicationFile $\& v=101>$ accessed 21 April 2021.

72 Ambrosius/Klement (n 35) 122

73 EMA, 'Rules for the implementation of Council Regulation (EC) No 297/95 on fees payable to the European Medicines Agency and other measures, Revised implementing rules to the Fee Regulation as of 1 April 2021', 29. Council Regulation (EC) No $297 / 95$ on the fees payable to EMA and its implementing regulations are currently under revision, $\mathrm{cf}<\mathrm{https}$ ://ec.europa.eu/info/ law/better-regulation/have-your-say/initiatives/2091-Revision-of -EMA-fees $>$ accessed 21 April 2021.

74 cf 1.1.1.1 Fee Regulation for the Authorisation and Registration of Medicinal Products - AMGKostV (Fee Schedule, 4), <https://www .bfarm.de/SharedDocs/Downloads/EN/Service/gebuehren/ AMGKostV-en.pdf?_blob=publicationFile \&v=8> accessed 21 April 2021. 
cedure has clear advantages. It allows to perform Union wide assessments with shared expertise and support of specialised advisory groups if needed. The sophisticated approach is reflected in the comparatively high fees. For the majority of medicinal products including those relevant for self-medication, those with long traditions, or those demanded in specific regions, the national/decentralised procedure with the more affordable fees are pursued. These national/decentralised procedures are of particular importance for SMEs and/or companies with regional focuses.

As the daily regulatory practice shows: Competent authorities at EU and national level as well as applicants are familiar with the stable historically grown multi-level architecture consisting of EMA Regulation, Community Code and national medicinal products laws. They have adjusted their organisations and processes accordingly. This structure which applicants are used to contributes to reliability and predictability. Both pillars (EMA Regulation with centralised procedure, Community Code with nation$\mathrm{al} /$ decentralised procedure) are required in practice and are heavily used by applicants. Also, from the practical perspective there is no need to change the established and logic structure of the basic pharmaceutical legislation.

\section{Directive or Regulation? Member States' View}

The idea of transposing the Community Code from a Directive into a Regulation is not new. Triggered

75 cf also Commission, '2019 Annual Burden Survey', $44<$ https://ec .europa.eu/info/sites/info/files/annual_burden_survey_2019_4 _digital.pdf> accessed 21 April 2021.

76 Commission, 'Decision of 19.5.2015 establishing the REFIT Platform' C(2015) 3261 final.

77 It was superseded by the Fit for Future Platform: Commission, 'Decision of 11.5.2020 establishing the Fit for Future Platform' C(2020) 2977 final.

78 REFIT Platform Opinion of 14.3.2019, Submission of Finish Government, 2 f, <https://ec.europa.eu/info/sites/info/files/xi.9.a _medicinal_products_for_human_use.pdf $>$ accessed 21 April 2021.

79 ibid 3, referring amongst others to CJEU, C-557/16 Astellas ECLI:EU:C:2018:181.

80 ibid Member State Opinions 2, 14, 15, 17.

81 ibid Member State Opinion 15. As noted above, such a uniform comprehensive codification is, however, practically hardly feasible. by a submission from the 'Finnish Government Stakeholder Survey on EU Legislation' in 2018 (Finnish Submission), the so-called 'REFIT Platform' collected views of Member States and other stakeholders on the option to replace the Community Code by a Regulation. ${ }^{75}$ The REFIT Platform brought together the Commission, national authorities and other stakeholders in regular meetings to improve existing EU Legislation. ${ }^{76}$ The platform consisted of a Government Group with one seat per Member State and a Stakeholder Group with 18 members and two representatives from the European Social Economic Committee and the Committee of the Regions. The REFIT Platform's mandate ended 31 October 2019. ${ }^{77}$

\section{Criticism voiced by the Finnish Submission}

The Finnish Submission, noting the trend towards the Regulation in the EU's pharmaceutical legislation saw the transposition of the Community Code into a Regulation as a logical next step to further harmonise national practices and legislation. ${ }^{78}$ Drawbacks of the Directive as the current legal form were derived from the detailed level of rules implemented nationally, resulting in double regulation and thereby higher administrative workload for the NCAs compared to a Regulation. Furthermore, a Regulation would lead to more specific legal terms than a Directive, thereby reducing the need for legal interpretation of EU pharmaceutical legislation both in the national courts and in the CJEU. ${ }^{79}$

\section{Opinions of Member States}

From the 17 Member States contributing to the Platform Opinion, four expressed some general support for a transposition into a regulation. ${ }^{80}$ One of them even proposed transposing all the relevant acquis in the field of medicinal products as far as possible into one single text. ${ }^{81}$ However, a detailed argumentation on the merits of a Regulation was not brought forward. Rather these Member States emphasised the need to evaluate the advantages and disadvantages of such a change of the legal form thoroughly beforehand. 
Other Member States saw some general advantages of a Regulation with regard to its direct application, but also mentioned the significant administrative burden during the period of national adaption to this field ${ }^{82}$ or would support the transposition into a Regulation only if the new legal act guarantees clear and precise rules and the elimination of different interpretations. ${ }^{83}$

However, the majority of Member States did not support the proposal to transpose the Community Code into a Regulation: ${ }^{84}$ They considered the system as sufficiently harmonised, striking the right balance between detailed provisions in some areas and more flexible ones for national rules in others. The Directive was properly implemented into national legislation and relevant activities were duly performed. ${ }^{85}$ These Member States saw no evidence that a regulation would lead to administrative simplification, cost reduction or the reduction of court cases. Regarding the latter, it was argued that most of the court cases concerning the Community Code concern divergent views on the interpretation of law and not on different implementation by Member States. ${ }^{86}$

Many of the contributing Member States also voiced the opinion that re-issuing the Directive as a Regulation would not substantially strengthen the internal market, nor harmonisation or legal certainty as such. The majority - with explicit reference to the 'very complicated, lengthy and painful' revision processes turning Directives into Regulations in the field of veterinary medicinal products, medical devices and clinical trials - warned that transformation of the Community Code into a Regulation would be a major operation for the EU and the Member States increasing immense administrative burden and cost, reducing predictability for all parties involved. ${ }^{87}$

\section{REFIT Platform Opinion}

Hence, the majority of Member States disagreed with the proposal to replace the Community Code with a Regulation; they stressed the need to avoid a complicated and lengthy transposition process. Instead, the Platform - in line with the considerations of the Stakeholder group - took the view that the Commission should explore ways to increase legal certainty, reduce administrative burden, lower costs, har- monise legislation and improve the operation of the internal market by undertaking an evaluation of the Community Code. ${ }^{88}$

\section{Third Take-Away (Member States' Perspective)}

The Member States' perspective as provided in the REFIT Platform Opinion in March 2019 confirms the findings of the formal and practical perspectives analysed under Sections II and III above. Many Member States emphasised the need for legislative freedom to fit the harmonised EU Law into their own legal system. In this context the practical problems encountered in previous revisions were of high importance.

\section{Experiences with Previous Revisions, particularly on Veterinary Medicinal Products}

When Member States pointed to implementation difficulties experienced during recent revisions turning Directives into Regulations they referred to the lengthy revision of the framework for veterinary medicinal products, ${ }^{89}$ on clinical trials ${ }^{90}$ and medical devices ${ }^{91}$. A detailed analysis of these revisions is outside the scope of this article, rather, by way of exam-

\footnotetext{
82 ibid Member State Opinions 7, 18. Member State Opinion 19 just supported an evaluation of the proposal.

83 ibid Member State Opinion 23.

84 ibid Member State Opinions 1, 4, 11, 12, 13, 16, 20, 21, 22.

85 ibid Member State Opinion 11.

86 ibid Member State Opinion 22.

87 ibid Member State Opinions 1, 11, 12, 16, 20, 21, 22.

88 ibid, 1 and Commission, (n 75) 44.

89 Regulation (EU) 2019/6 of the European Parliament and of the Council of 11 December 2018 on veterinary medicinal products and repealing Directive 2001/82/EC [2019] OJ L4/43. For a first overview cf Heinz-Uwe Dettling/Stefan Schmidt, 'Neues Tierarzneimittelrecht 2022' (2021) PharmR $178 \mathrm{ff}$.

90 (n 30).

91 Regulation (EU) 2017/745 of 5 April 2017 on medical devices [2017] O] L117/1, entered into force just under five years after the publication of the Commission's legislative proposal. It replaces Directives 923/42/EEC and 90/385/EEC and was originally to apply from 16.5.2020. This date was postponed for one year by Regulation (EU) 2020/561 of 23 April 2020 [2020] O] L130/18.
} 
ple the revision in the veterinary field and on clinical trials will be briefly summarised.

\section{EU Legal Framework on Veterinary Medicinal Products}

\section{a. EU Level: The New Regulation on Veterinary Medicinal Products}

In the recent revision on veterinary medicinal products, Directive 2001/82/EC (being very similar to Directive 2001/83/EC on human medicinal products) and the rules on the central marketing authorisation for veterinary medicinal products from the EMA Regulation were transposed into Regulation (EU) 2019/6 (VMP Regulation) ${ }^{92}$. This Regulation entered into force in January 2018 , four and a half years after the publication of the Commission's legislative proposal in 2014. It applies from 28 January 2022 (Article 160 VMP Regulation).

The intended positive effect of consolidating the veterinary medicinal products legislation into one Regulation is to a certain extent mitigated by the fact that also the VMP Regulation requires the adoption of almost 30 delegated and implementing acts ${ }^{93}$ triggering additional complexity. This example showed: The concept of breaking with an established multilevel structure by merging different legal acts into one basic regulation is highly sophisticated. Gaps, various topics still to be addressed in delegated and

92 (n 89)

93 The progress on these acts can be followed on the dedicated websites of the Commission <https://ec.europa.eu/food/animals/ health/veterinary-medicines-and-medicated-feed/imp-regs-2019 _en > and EMA <https://www.ema.europa.eu/en/veterinary -regulatory/overview/veterinary-medicines-regulation $>$ accessed 21 April 2021.

94 CJEU, C-34/73 Variola v Amministrazione Italiana delle Finanze ECLI:EU:C:1973:101, paras 10-11.

95 CJEU, C-272/83 Commission v Italy ECLI:EU:C:1985:147, paras 26-27.

96 CJEU, C-40/69 Hauptzollamt Hamburg Oberelbe v Bollmann ECLI:EU:C:1970:12, para 4.

97 cf Dettling/Schmidt (n 89) 189

98 The Federal Ministry of Health published the governmental draft on 24.3.2021, <https://www.bundesgesundheitsministerium.de/ fileadmin/Dateien/3_Downloads/Gesetze_und_Verordnungen/ GuV/T/TAMG_GE_Kabinettfassung.pdf $>$ accessed 21 April 2021.

99 (n 15)

100 cf Dettling/Schmidt (n 89) 180 ff. implementing acts and new questions to be clarified by courts can hardly be avoided.

\section{b. National Level: Germany as Example}

As the VMP Regulation will become directly applicable in January 2022, existing national laws implementing the former Directive 2001/82/EC on veterinary medicinal products will largely become obsolete. Due to the direct application (Article 288(2) TFEU) of a Regulation, measures of transposition into national law which could potentially conceal the European nature of the provision and thus subvert the jurisdiction of the CJEU are not permissible. ${ }^{94}$ The primacy of EU law does in principle not allow the repetition of provisions of the Regulation in national law. By way of exception the CJEU accepted in one case the incorporation of elements of Regulations in national law for the sake of coherence because of special circumstances, created by the combination of multi-level provisions (European, national, regional).$^{95}$ Apart from this, Member States may introduce national measures only insofar as they are explicitly empowered by the Regulation or to fill unintended legal gaps. ${ }^{96}$

This complex interplay between the directly applicable Regulation and national legislation for areas of law previously covered by a Directive leads to extensive legal uncertainty as the consequences of the Veterinary Regulation for the German legislation shows. ${ }^{97}$ There, the Federal German Government under the shared responsibility of two Ministries (Federal Ministry of Health and Federal Ministry of Food and Agriculture) drafted a legislative proposal ${ }^{98}$ which is currently in deliberations in the two chambers of the German Parliament (Bundestag and Bundesrat).

In Germany, until now veterinary medicinal products have been regulated together with medicinal products for human use in the 'AMG. ${ }^{99}$ The German legislator chose to adapt the current law to the VMP Regulation by erasing all the provisions on veterinary medicinal products from the AMG and to create a new Veterinary Medicinal Products Act ('Tierarzneimittelgesetz'). This new legislation will be fragmented. ${ }^{100}$ Thereby, the new architecture and interplay of EU and national legislation and the overhaul of the historically developed legal system lead to substantial extra costs and administrative burdens. The adaption to the new legal environment is especially difficult to manage for SMEs, which in Germany hold 
many marketing authorisations for veterinary medicinal products issued by the NCA.

\section{EU Rules on Clinical Trials}

Another example that a Regulation does not necessarily lead to a higher degree of harmonisation and clarification is the Clinical Trial Regulation ${ }^{101}$. Despite having been published in the Official Journal of the EU on 27 May 2014, it is still not applicable in the EU in major parts. ${ }^{102}$ The transposition time, which will still apply when the Regulation becomes fully applicable, will add further uncertainty for companies and NCAs. Furthermore, administrative burden was not decreased at least in some parts as the demarcation between interventional and non-interventional studies shows. While the Regulation includes a definition of the term 'noninterventional study' in Article 2(2) No 4 it is almost certain that the differences among EU Member States in interpreting this definition will remain.

\section{Forth Take-Away (Experiences with Previous Revisions)}

The previous revisions on veterinary medicinal products, clinical trials and medical devices certainly addressed relevant issues and achieved solutions. However, the changes in the legal form from a Directive into a Regulation, did not only increase complexity, but - as a sort of counterproductive consequence also legal uncertainty. Existing national laws are largely no longer required and undergo complex transformations.

\section{Directive or Regulation - The EU Primary Law Perspective}

In the following, criteria for the choice of the suitable legal act shall be analysed from the perspective of primary EU law.

\section{Choice of Legal Act in the Evolution of EU Pharmaceutical Law}

Since the launch of the internal market in the 1980 s and still at the time of the introduction of the Com- munity Code in 2001, the Directive constituted the dominant type of legislative act for the gradual approximation of national law, also in the area of health, setting out binding results on Member States, but giving them some flexibility and legislative freedom to fit the harmonised substantive EU Law into their own legal system. ${ }^{103}$ Generally, harmonisation of Member States' laws by means of the Directive was used in particular for areas of law with already differentiated national legislation and regulatory contexts. By contrast, the Regulation was seen as the appropriate instrument for the unification of laws in areas where homogeneous national legal systems did not yet exist. ${ }^{104}$

Accordingly, for the Community Code, codifying various previous medicinal products related Directives, the legislator again chose this legislative instrument. Thereby, the establishment of a common legal framework allowing the maintenance of existing national laws, where needed, was achieved. ${ }^{105}$ The Directive as the appropriate legislative instrument has been upheld for the vast majority of amendments of the Community Code.

In contrast, the introduction of the centralised marketing authorisation procedure as an EU uniform procedure and the establishment of EMA as the specialised regulative EU agency ${ }^{106}$ in 2004 needed legislative action by means of a Regulation. This is pre-

\section{1 (n 30).}

102 In its update of 21 April 2021 EMA's Management Board indicated that the Clinical Trial Information System (CTIS) is aimed to go live on 31 January 2022, six months after the Commission publishes a notice confirming the full functioning of CTIS. As of this date the Regulation would apply, <https://www.ema.europa.eu/ en/human-regulatory/research-development/clinical-trials/clinical -trial-regulation> accessed 21 April 2021.

103 cf Fleischfresser (n 54) $\$ 3$ para 4; generally regarding choice of the legal instrument: Bernd Bievert in Jürgen Schwarze/Ulrich Becker/Armin Hatje/Johann Schoo (eds), EU-Kommentar (4th edn, Nomos 2019) Art 288 TFEU para 23.

104 Jürgen Schwarze/Ulrich Becker/Christiana Pollak, The Implementation of Community Law - Studies in the Legislative and Administrative Policies of the European Community and its Member States, (Nomos 1994) 67 ff; cf also Jürgen Schwarze/Inge Govaere/Frédérique Hélin/Peter Van den Bossche (eds), The 1992 Challenge at National Level - a community-wide joint research project on the realization and implementation by national governments and business of the internal market programme, vol I-III (Nomos 1990, 1991, 1993)

105 cf Commission, 'Report to the European Parliament and Council on the Application of Directives 92/73 and 92/74' COM(97) 362 final, 2.

106 The regulative agencies are to be distinguished from the executive agencies, which are entrusted with certain tasks in the management of Community programmes, see Regulation 58/2003 of 19 December 2002 [2003] OJ L11/1. 
determined by Article 298(2) TFEU, which requires action by means of Regulations for the settlement of the inner organisation of the institutions, bodies, offices and agencies of the Union. Accordingly, also the EU legislation on medicinal products for paediatric use $^{107}$ and on advanced therapy medicinal products ${ }^{108}$ were then issued in the legal form of a Regulation, both having a strong relation to the EMA Regulation. Medicinal products for paediatric use under certain circumstances are eligible for the centralised procedure, advanced therapy medicinal products even mandatorily require centralised authorisation according to Annex I No 1a) EMA Regulation. Furthermore, these two legal acts established amongst others the Paediatric Committee and the Committee for Advanced Therapies within EMA.

Examples for recent measures regarding EU agencies are the Commission's current proposals for Regulations to strengthen the EMA and ECDC ${ }^{109}$ and to establish a new EU Health Emergency Preparedness and Response Authority ('HERA') ${ }^{110}$ in reaction to the COVID-19 pandemic. For the establishment or strengthening of EU Agencies and related procedures the reasons for the choice of a Regulation are obvious. Such obvious reasons were, however, not given in other recent revisions of the EU's pharmaceutical legislation where Directives were replaced by Regu-

107 (n 27). This regulation is currently also under revision as part of the EU Pharmaceutical Strategy, cf Commission, 'Inception Impact Assessment' Ref. Ares(2020)7081640.

108 (n 29); cf also the European Commission and EMA 'Action Plan on ATMPs' (Status Update: February 2020) aiming at improving their regulatory framework, <https://www.ema.europa.eu/en/ documents/other/european-commission-dg-health-food-safety -european-medicines-agency-action-plan-advanced-therapy_en .pdf> accessed 21 April 2021.

109 Commission, Proposals for a Regulation on a reinforced role for EMA, COM(2020) 725 final and for a Regulation amending Regulation (EC) No 851/2004 establishing ECDC, COM(2020) 726 final.

110 Commission, 'Inception Impact Assessment: European Health Emergency Preparedness and Response Authority' Ref. Ares(2021)674649.

111 On the evolution of the principle of proportionality in the case law cf Jürgen Schwarze, European Administrative Law (Sweet \& Maxwell 2006), Introduction, cxxxix ff and $677 \mathrm{ff}$

112 [1997] OJ C340/105, 106.

113 [2012] OJ C326/206.

114 Commission, 'Report on subsidiarity and proportionality' $\operatorname{COM}(2010)$ 547, 3; Paul Craig/Gráinne de Búrca, EU Law (7th edn, Oxford University Press 2020) 203 f.

115 cf Commission, 'Better Regulation Toolbox, Tool \#5. Legal basis, subsidiarity and proportionality' $30,<$ https://ec.europa.eu/ info/sites/info/files/file_import/better-regulation-toolbox-5_en_0 .pdf $>$ accessed 21 April 2021. lations, eg on veterinary medicinal products, medical devices and clinical trials. This general trend in the EU's pharmaceutical legislation to replace Regulations by Directives shall be examined against the background of primary EU law.

\section{EU Primary Law Governing the Choice of Legal Act}

\section{a. Discretion of the EU Legislator and Principle of Proportionality}

According to Article 17(2) TFEU, generally the Commission has the right of legislative initiative. When choosing the suitable legal act, the Commission has discretion which is to be exercised in observance of the principle of proportionality, as laid down in Article 296 TFEU. This provision foresees that where the type of act to be adopted is not specified by the Treaties the institutions shall select it on a case-bycase basis, in compliance with the applicable procedures and with the principle of proportionality.

The principle of proportionality stipulates that the content and form - including the choice of the appropriate legal act - of EU action shall not exceed what is necessary to meet the pursued objectives (Article 5(4) TFEU). ${ }^{111}$ With respect to the appropriate type of legal act, the Protocol on the application of the principles of subsidiarity and proportionality annexed to the Amsterdam Treaty explicitly stated that 'The form of Community action shall be as simple as possible, consistent with satisfactory achievement of the objective of the measure and the need for effective enforcement. The Community shall legislate only to the extent necessary. Other things being equal, directives should be preferred to regulations and framework directives to detailed measures. ${ }^{112}$

Although this clear preference for the Directive was - as many parts of the guidelines contained in the much more extensive Amsterdam Protocol - not transposed to the according Protocol (No 2) to the Lisbon Treaty on the application of the principles of subsidiarity and proportionality ${ }^{113}$, the further use of these guidelines was declared by the Commission $^{114}$ and in principle incorporated in its better regulation guidance. Accordingly, the Commission when choosing the suitable legal form has to ensure that the policy approach and its intensity match the identified problem and objective. ${ }^{115}$ The choice of 
the legal form needs to be accompanied by solid justification. ${ }^{116}$ In the Commission's own words, 'it is about carefully matching the intensity of the proposed measure with what is to be achieved'. ${ }^{117}$ Thereby, any financial and administrative burden falling on the EU, national governments, authorities and economic operators must be minimised and commensurate with the targeted purpose. ${ }^{118}$

The principle of proportionality will for example not be observed if the action taken by the EU does not address national specificities, such as methodologically different concepts, which might be justified and necessary for the functioning of the effective and efficient supply of medicinal products in some Member States. ${ }^{119}$ It is therefore reasonable to apply so called 'true proportionality' and also ask whether a measure is also proportional to the pursued objectives, notably whether the costs in Member States interests are disproportionately large. ${ }^{120}$ The principle of proportionality aims moreover at protecting Member States from being deprived of their autonomy and discretionary powers where this is not appropriate and necessary, thereby ensuring the adherence of the national sovereignty and identity. ${ }^{121}$ This protection with a view to the choice of the legal act takes place through choosing the least burdensome legislative instrument.

In this respect, the Directive, due to its binding effect limited to the objective to be achieved, enables a less invasive adjustment of national legal orders, maintaining their unity and consistency. ${ }^{122}$ Therefore, the EU legislator - although having discretion in the choice of the type of its actions - should gen-

116 ibid

117 Commission, 'Communication on the principles of subsidiarity and proportionality: Strengthening their role in the EU's policymaking' $\operatorname{COM}(2018) 703$ final, 3.

$118 \mathrm{cf}$ also Art 5 of the Protocol (No 2) (n 113).

119 cf ibid Art 2: '(..) take into account the regional and local dimension of the action envisaged'.

120 Gareth Davies, 'Subsidiarity: The Wrong Idea, in the Wrong Place, at the Wrong Time' (2006) CMLRev 63, 71, $82 \mathrm{ff}$, who concludes that ' $(. .$.$) given there is no other principle which can$ prevent important national measures, and important national autonomy, falling victim to less important Community action, the Court should apply proportionality fully', 83.

121 Maria Geismann in Hans von der Groeben//ürgen Schwarze/Armin Hatje (eds), Europäisches Unionsrecht (7th edn, Nomos 2015) Art 296 TFEU para 3.

122 Nina Wunderlich/Thomas Pickartz, 'Hat die Richtlinie ausgedient? Zur Wahl der Handlungsform nach Art 296 Abs. 1 AEUV (2014) EuR, 659, $663 \mathrm{f}$. erally give priority to the directive when both types of legal acts are suitable with a view to the objectives pursued. ${ }^{123}$ This approach is also in line with the principle of subsidiarity as laid down in Article 5(3) TEU, which - in a nutshell - aims at ensuring the ability of Member States to take decisions and actions, so that that competences are exercised as closely as possible to the citizens of the Union. ${ }^{124}$ This aim can in principle be better achieved by EU measures in the form of a Directive, leaving more room for national implementation and maintenance of existing legal structures. The flexibility in the transposition provided for by the Directive is especially important for Member States with a federal structure which has to be respected.

\section{b. Division of Competences in the Field of Health}

Finally, also the division of competences between EU and Member States needs to be taken into account when evaluating the suitable legal form of an EU measure. As regards the regulation of medicinal products, it was not until the Treaty of Lisbon that the Union was empowered with (shared) competence of the regulation of high standards for the safety and quality of medicinal products and medical devices (Article 168(4)(c) TFEU). ${ }^{125}$ Under the current competence framework, the EU shall ensure a high level of human health protection in the definition and implementation of all Union policies and activities ${ }^{126}(\mathrm{Ar}-$ ticle 168(1) $1^{\text {st }}$ sentence TFEU ${ }^{127}$, also referred to as 'health in all policies' approach $\left.{ }^{128}\right)$. Furthermore,

123 Georg Lienbacher in Schwarze et al, EU-Kommentar (n 103) Art 5 TEU para 37; Wunderlich/Pickartz (n 122) 659, $662 \mathrm{f}$.

124 cf recital 13 of the Preamble of the Consolidated Version of the Treaty on European Union, recital 13 [2012] OJ C326/13, 16 and Protocol (No 2) (n 113), first recital.

125 Until then, the EU possessed merely a supportive EU competence in the field of human health protection under the Treaties (ex-Art 152(4)(c) TEC).

126 Thus, considered a 'mainstreaming' provision or 'integration clause', see references in Mary Guy/Wolf Sauter, 'The History and Scope of EU Health Law and Policy' (TILEC, 2016) 12

127 Art 168 TFEU replaced ex-Art 152 TEC with the Treaty of Lisbon, Consolidated Version [2012] OJ C326/47. Ex-Art 152 TEC has been introduced with the Treaty of Amsterdam (n 10) and remained unmodified in the Treaty of Nice, Consolidated Version [2002] OJ C325/1.

128 Eleanor Brooks/Mary Guy, 'EU Health law and policy: shaping a future research agenda (2020) Health Economics, Policy and Law, 1, 3; Tobias Maass/Florian Schmidt, 'Die Entwicklung des EUGesundheitsrechts seit 2012' (2015) EuZW, 85. 
based on Article 168(1) and (5) TFEU ${ }^{129}$ the EU can act only in a complementary, supportive and coordinating way to protect and improve human health and combat serious cross-border threats (including surveillance and early warning systems) without harmonising the Member States' law. ${ }^{130}$

Thus, in accordance with the principle of conferral, the general legislative competence in public health lies with the Member States - the latter being however in their legislation still bound by the internal market integration policy. ${ }^{131}$ The utter limit of any EU action in the field of public health and in particular of any harmonisation actions based on Article 168(4)(c) TFEU is manifested in Article 168(7) TFEU. ${ }^{132}$ Accordingly, the definition of the health policy and the organisation and delivery of health services and medical care fall in the responsibility of the Member States. Article 168(7) TFEU emphasises and substantiates for the field of health the principle of general subsidiarity of EU action in areas where the EU has no exclusive competence. ${ }^{133}$

Taking this into account, also from a competence point of view the approximation of national laws in the sensitive and complex area of medicinal products seems preferably done by way of a Directive.

\section{Fifth Take-Away (Primary EU Law Perspective)}

Without doubt the maintenance of the legal instrument of a Regulation is necessary and proportional

\footnotetext{
129 In conjunction with Art 2(5) and Art 6(a) TFEU.

130 The EU has also supportive competence to foster the international cooperation in the field of public health (Art 168(3) TFEU) and the coordination between the Member States, in order to improve the complementarity of their health systems in cross-border areas (Art 168(2) TFEU).

131 cf Communication from the Commission, 'Guidelines on the optimal and rational supply of medicines to avoid shortages during the COVID-19 outbreak' [2020] OJ C116I/1, concerning national export bans for medicines within the EU during the COVID-19 crisis, which were not in line with the Treaty; Craig/de Búrca (n 114) 115.

132 cf Werner Berg/Steffen Augsberg in Schwarze et al, EU-Kommen$\operatorname{tar}$ (n 103) Art 168 TFEU para 36; Birgit Schmidt am Busch, in Eberhard Grabitz/Meinhard Hilf/Martin Nettesheim (eds), Das Recht der Europäischen Union (C.H.Beck 2020) Art 168 TFEU para 82. Contrary, the harmonisation exclusion of Art 168(5) TFEU does not apply to measures as foreseen in Art 168(4)(c), but only to incentive measures for the health protection etc as outlined in Art 168(5), cf Frank Niggemeier, in von der Groeben/Schwarze/Hatje, Europäisches Unionsrecht (n 121) Art 168 TFEU para 34.

$133 \mathrm{cf}$ Guy/Sauter (n 126) 12 ff.
}

for the EU uniform centralised marketing authorisation. In contrast to a Regulation, in line with Article 296(1) TFEU and the principles of proportionality and subsidiarity, the Directive gives the necessary leeway to the Member States for national implementation and adaption. Therefore, also from the primary law perspective the Directive still constitutes the more suitable and preferable type of act to regulate the national/decentralised procedures and to approximate national laws in sensitive fields like medicinal products, where - notwithstanding the shared competences now foreseen by Article 168(4) TFEU - the issues of health policy, health care and their enforcement still remains inherently a responsibility of Member States.

\section{Conclusion}

Discussions among Member States whether to transpose the Community Code into a Regulation had already arisen in 2019. The majority of Member States did not support it. They referred to the experiences in other areas where Directives were transposed into Regulations (veterinary medicinal products, clinical trials, medical devices). There, after lengthy procedures the adaptions to the new EU Regulation regime broke with the existing legal architecture and fragmented existing national law. Stakeholders involved are still investing efforts and costs to reorganise their processes, structure and systems accordingly. This is a particular challenge for SMEs.

The coexistence of Community Code and EMA Regulation goes back to 2004. To regulate the centralised marketing authorisation procedure and topics related to the EMA the Regulation is the most suitable legal form. In practice the majority of medicinal products including those relevant for self-medication, with long traditions, with known substances and those being demanded in specific regions, are, however, assessed by NCAs according to the national law implementing the Community Code. The national/decentralised procedures are of specific relevance for SMEs.

Generally, authorities and applicants are familiar with this structure which functions well in the daily regulatory practice. However, as the exceptional circumstances during the COVID-19 pandemic revealed, certain amendments are required, including the speeding up of the authorisation process and more 
flexibility. The envisaged legislative review should address the topics to be improved, but without causing damage to the existing functioning structure. The Commission's 'targeted review' identifying the provisions requiring amendments while leaving the other ones unaffected is, therefore, a well-considered approach. Against the background of ambitious time- lines, the Member States' and primary EU law perspective and the experiences with previous revisions, a break with the existing legal forms is to be avoided in the upcoming review. Instead, the legislator should strive for achieving its objectives within the existing legal structure. As a result, the Community Code's legal form of a Directive should be maintained. 